\title{
Temperature dependence of electric conduction in polyimides with main chain triphenylamine structures
}

\author{
Kazuhiro Takizawa, Shigeo Asai and Shinji Ando
}

The temperature dependence of electric current was investigated in polyimides (PIs) with different chemical structures to clarify the electric conduction mechanisms in PI films. The current density of the PIs with main chain triphenylamine (TPA) structures (pyromellitic dianhydride/4,4'-diamino-4'"-methyltriphenylamine (DATPA) and 3,4,3',4'-biphenyltetracarboxylic dianhydride/ DATPA) significantly increased above $120^{\circ} \mathrm{C}$. This was most likely due to an exponential increase in the number of thermally excited electron carriers. This interpretation was supported by a comparison of the activation energies $\left(E_{\mathrm{a}}\right)$ obtained from the temperature dependence of the current density and the energy gaps $\left(E_{\mathrm{g}}\right)$ estimated by cyclic voltammetry. In contrast, the current densities of fully aromatic and semi-aliphatic PIs without TPA structures exhibited much smaller temperature dependencies. The limited number of thermally excited carriers in these PIs (due to their large $E_{\mathrm{g}}$ values) suggests that the ionic current is the dominant factor, rather than the electronic current.

Polymer Journal (2014) 46, 201-206; doi:10.1038/pj.2013.93; published online 15 January 2014

Keywords: electric conduction; polyimide; temperature dependence; triphenylamine structure

\section{INTRODUCTION}

Fully aromatic polyimides (PIs) derived from pyromellitic dianhydride and bis(4-aminophenyl)ether (PMDA/ODA) or from 3,3', $4,4^{\prime}$-biphenyltetracarboxylic dianhydride and $p$-phenylene diamine (s-BPDA/PPD) represent super-engineered plastics that exhibit high thermal and chemical stability, flame resistance, radiation resistance, mechanical strength, insulating properties and good flexibility. ${ }^{1}$ Therefore, PIs have been widely employed in integrated circuits, semiconductor devices and electronic components. In addition, PIs have a variety of functionalities that make them an attractive new class of thermally stable electronic and optical materials. ${ }^{2-9}$ For example, PIs containing triphenylamine (TPA) structures and their derivatives have been applied to memory devices, photogeneration and electrochromic materials. ${ }^{4-6,9}$

The electrical conduction behaviors of PMDA/ODA films have been investigated by several research groups. ${ }^{10-19}$ Sawa et al. ${ }^{13}$ studied the electric conduction current of PMDA/ODA films at temperatures of $120-180^{\circ} \mathrm{C}$ and applied electric fields of $4-500 \mathrm{kV} \mathrm{cm}^{-1}$. They concluded that the conduction in the PI films is caused by ionic hopping. Sessler et al..$^{15}$ studied two-side metallized PMDA/ODA films to investigate interface-controlled currents. They also examined oneside metallized film subject to positive-corona charge injection to investigate bulk-controlled currents. The electric currents measured from the one-side metallized films were significantly larger than those measured from the two-side metallized films at temperatures below $200{ }^{\circ} \mathrm{C}$. Thus, the currents measured for the two-side metallized films were considered to be interface controlled. This indicates that both enhancement in the charge mobility and an increase in the number of electronic carriers in the bulk are necessary to improve the conductivity of PIs. Lee et al. ${ }^{17-19}$ investigated the photoconductivity of semi-aliphatic 4,4'-diaminodicyclohexylmethane (PMDA/DCHM) PI films. They reported that a charge-transfer complex is formed in the excited state when an optical absorption band assignable to weak intermolecular interactions is excited, and the charge-transfer complex subsequently produces charge carriers of radical cations and radical anions. This mechanism can lead to the generation of photoconductivity in the bulk PI. Although PIs containing TPA structures represent an interesting new class of optoelectronic materials, their electric conduction mechanisms have not yet been investigated. In this study, the elapsed time and temperature dependence of electric current were investigated for thin film PIs having different chemical structures, including incorporation of TPA.

\section{EXPERIMENTAL PROCEDURE}

Materials

Pyromellitic dianhydride (PMDA) purchased from Kanto Chemical Co., Inc. (Tokyo, Japan), was dried and purified by sublimation under reduced pressure. $s$-BPDA, which was purchased from Wako Pure Chemical Industries, Ltd (Osaka, Japan), was dried at $170{ }^{\circ} \mathrm{C}$ for $12 \mathrm{~h}$ under reduced pressure. $4,4^{\prime}$ Diamino- $4^{\prime \prime}$-methyltriphenylamine (DATPA), which was kindly supplied by JSR Co., Ltd (Tokyo, Japan), was sublimated under reduced pressure. PPD and ODA, which were purchased from Wako Pure Chemical Industries, Ltd, were recrystallized from tetrahydrofuran, followed by sublimation under reduced pressure. DCHM, which was purchased from Tokyo Kasei Kogyo Co., Ltd (Tokyo, Japan), was recrystallized from $n$-hexane, followed by sublimation 
under reduced pressure. The content of the trans-trans isomer in the purified DCHM was estimated at $94 \%$ by ${ }^{1} \mathrm{H}$ nuclear magnetic resonance spectrometry. ${ }^{20} \mathrm{~N}, \mathrm{O}$-Bis(trimethylsilyl)trifluoroacetamide $(99+\%$, BSTFA $)$ and $\mathrm{N}, \mathrm{N}$-dimethylacetamide (anhydrous) were purchased from Aldrich (St Louis, MO, USA) and used without further purification.

\section{Preparation of PI films}

The molecular structures of the PIs used in this study are shown in Figure 1. To investigate the effects of a TPA structure on the main chain on the electrical properties of the PIs, PMDA/DATPA and $s$-BPDA/DATPA PIs along with fully aromatic PMDA/ODA and $s-\mathrm{BPDA} / \mathrm{PPD}$ PIs, which are widely used for industrial applications, and semi-aliphatic PMDA/DCHM and $s$-BPDA/ DCHM PIs were studied. The precursors of the aromatic PIs, poly(amic acid)s, were prepared by mixing equimolar amounts of dianhydride and diamine in a $\mathrm{N}, \mathrm{N}$-dimethylacetamide solution under dry nitrogen. The precursors of the PMDA/DCHM and s-BPDA/DCHM, poly(amic acid) silylesters, were prepared by in situ silylation..$^{21-23}$ The details of the synthetic procedures for the poly(amic acid) silylesters are reported elsewhere. ${ }^{24,25}$ The $N, N$-dimethylacetamide solutions of the poly(amic acid)s and poly(amic acid) silylesters were spin-coated onto indium tin oxide (ITO) substrates, followed by soft-baking at $25^{\circ} \mathrm{C}$ for $0.5 \mathrm{~h}$ and baking at $70{ }^{\circ} \mathrm{C}$ for $1 \mathrm{~h}$ with a subsequent one-step thermal imidization procedure. The final curing conditions were $300^{\circ} \mathrm{C} / 1.5 \mathrm{~h}$ for the PMDA/DATPA, s-BPDA/DATPA, PMDA/DCHM and $s$-BPDA/DCHM films and $350^{\circ} \mathrm{C} / 1.5 \mathrm{~h}$ for the PMDA/ $\mathrm{ODA}$ and $s$-BPDA/PPD films. The heating rate was $4.6^{\circ} \mathrm{C} / \mathrm{min}$ from $70^{\circ} \mathrm{C}$ to the final curing temperatures. The curing procedures were conducted under vacuum. The completion of the thermal imidization was confirmed by observing the attenuated total reflection Fourier transform infrared (ATRFT-IR) spectra of the PI films (see Supplementary Figure 1 in the Supporting Information). Silver electrodes were directly formed on the PI films by magnetron sputtering through a mask under vacuum. The PI films used for cyclic voltammetry $(\mathrm{CV})$ measurements were prepared on Au substrates by thermal imidization of the poly(amic acid) and poly(amic acid) silylester films under a nitrogen atmosphere.

\section{Measurements}

Ultraviolet-visible (UV/Vis) absorption spectra were measured using a Hitachi U-3500 spectrophotometer. The film thicknesses were measured with a probepin type surface profilometer (DEKTAK-III). For electrical measurements, the PI samples were placed in an electrically shielded aluminum box. ITO glass was used as a front electrode, and a thin silver layer was evaporated on the other surface to serve as a back electrode $(\phi=3 \mathrm{~mm})$ with a surrounding guard electrode. The electric current was measured using a pico-ammeter (ADC Co., Ltd, Tokyo, Japan, 8340A) under a nitrogen atmosphere with varying sample temperatures and elapsed time periods from the application of the voltage. The samples were dried at $240^{\circ} \mathrm{C}$ for $30 \mathrm{~min}$ before measurement. The temperatures of samples were controlled with a ceramic heater directly attached to the ITO glass. CV experiments were conducted using a three-neck electrochemical cell. A clean O-ring (10 mm diameter) in a cylindrical cavity surrounding a hole in the bottom of the cell was placed between the cell and the PI films coated on Au substrates, which served as working electrodes. The cell was filled with $0.2 \mathrm{M}\left(\mathrm{Bu}_{4} \mathrm{~N}\right) \mathrm{PF}_{6}$ (tetrabutylammonium hexafluorophosphate) in purified acetonitrile, which was deoxygenated by three cycles of freeze-pump-thaw treatment. A platinum $(\mathrm{Pt})$ wire was used as a counter electrode. The cell was referenced to a silver $(\mathrm{Ag})$ wire. The sweep rate was set to $50 \mathrm{mV} \mathrm{s}^{-1}$. Ferrocene was used as an external reference for calibration (highest occupied molecular orbital (HOMO): $-4.80 \mathrm{eV})$

\section{Quantum chemical calculations}

The density functional theory was adopted using a three-parameter Becke-style hybrid functional (B3LYP) $)^{26-28}$ for the calculations of the electronic structures of the imide compounds. The $6-311 \mathrm{G}(\mathrm{d})$ basis set was used for the geometry optimizations. ${ }^{29-31}$ The van der Waals volumes were calculated based on the Slonimski's method ${ }^{32}$ using optimized geometries, in which we used the van der Waals radii of the atoms reported by Bondi. ${ }^{33}$ All calculations were performed with the Gaussian- $09^{34}$ program package installed at the Global Scientific Information and Computing Center, Tokyo Institute of Technology.

\section{RESULTS AND DISCUSSION}

\section{CV measurements}

The electrochemical and optical properties of the PI films were investigated by CV and UV/Vis absorption spectroscopy, respectively. Figures $2 \mathrm{a}-\mathrm{d}$ show the cyclic voltammograms of PMDA/DATPA, PMDA/ODA and PMDA/DCHM PI films coated on the Au substrates with a cyclic voltammogram of ferrocene as a reference. The PIs exhibited two reversible one-electron reductions at -0.8 and $-1.3 \mathrm{~V}$. The first reduction corresponds to the formation of the radical anions of the pyromellitic moiety, and the second one corresponds to the formation of dianions. ${ }^{35}$ The HOMO and lowest unoccupied molecular orbital (LUMO) energy levels of the PIs can be estimated from the oxidation and reduction half-wave potentials $\left(E_{1 / 2}\right)$ relative to the oxidation half-wave potential of a standard ferrocene reference (HOMO: $-4.80 \mathrm{eV}$ ). Although PMDA/DATPA exhibited one oxidation curve, of which the peak-top was $1.2 \mathrm{~V}$, PMDA/ODA and PMDA/DCHM exhibited large electric currents because of electrical breakage at higher positive potentials. Thus, the HOMO levels of<smiles>Cc1ccc(N(c2ccc(C(C)C)cc2)c2ccc(-n3c(=O)c4cc5c(=O)n(C)c(=O)c5cc4c3=O)cc2)cc1</smiles>

PMDA/ODA<smiles>Cc1ccc(Oc2ccc(-n3c(=O)c4cc5c(=O)n(C)c(=O)c5cc4c3=O)cc2)cc1</smiles><smiles>CCN1C(=O)c2ccc(-c3ccc4c(c3)C(=O)N(c3ccc(C)cc3)C4=O)cc2C1=O</smiles>

$s$-BPDA/PPD
PMDA/DCHM<smiles>CC1CCC(CC2CCC(n3c(=O)c4cc5c(=O)n(C)c(=O)c5cc4c3=O)CC2)CC1</smiles>

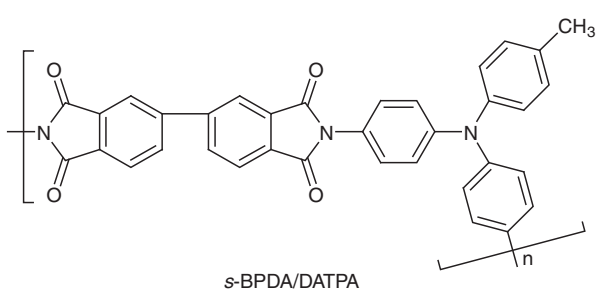<smiles>CN1C(=O)C2=CCC=CC2C1=O</smiles><smiles>CC1(C)CCC(CC2CCC(N3C(=O)c4ccccc4C3=O)CC2)CC1</smiles>

$s$-BPDA/DCHM

Figure 1 Chemical structures of the polyimides (PIs). DATPA, 4,4'-diamino-4"'-methyltriphenylamine; DCHM, diaminocyclohexylmethane; ODA, bis(4aminodiphenyl) ether; PMDA, pyromellitic dianhydride; PPD, p-phenylenediamine; s-BPDA, 3,3',4,4'-biphenyltetracarboxylic dianhydride. 

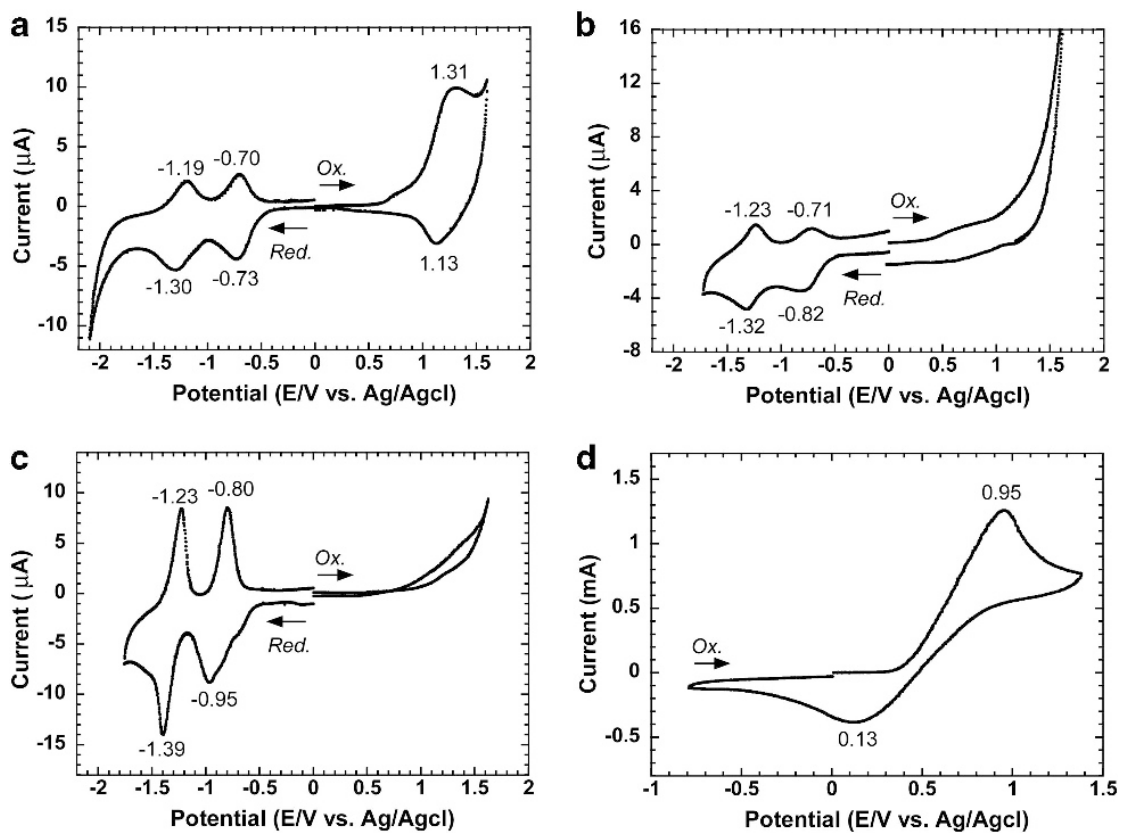

Figure 2 Cyclic voltammetric diagrams for (a) pyromellitic dianhydride (PMDA)/4,4'-diamino-4'"-methyltriphenylamine (DATPA), (b) PMDA/4,4'diaminodiphenyl ether (ODA) and (c) PMDA/diaminocyclohexylmethane (DCHM) PI films compared with (d) ferrocene.

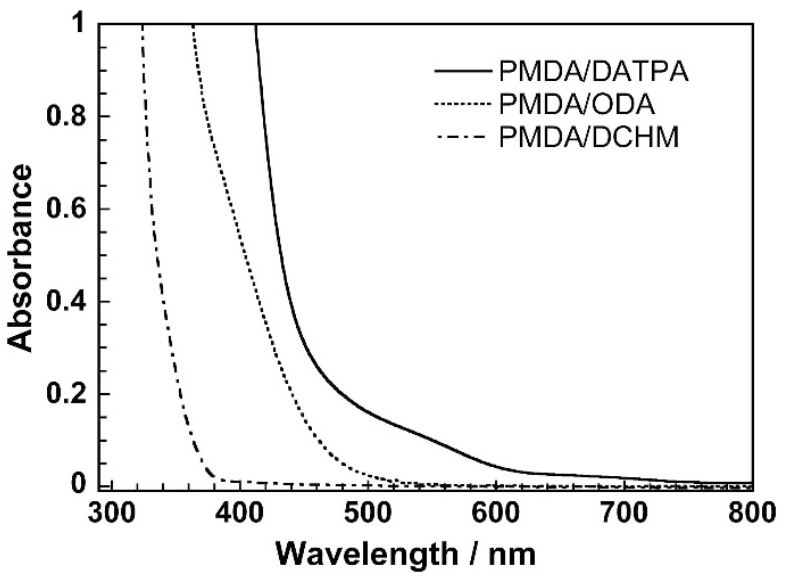

Figure 3 Ultraviolet-visible absorption spectra for the polyimide (PI) films (approximately $1.0 \mu \mathrm{m}$ thick). DATPA, 4,4'-diamino-4"'-methyltriphenylamine; DCHM, diaminocyclohexylmethane; ODA, bis(4-aminodiphenyl) ether; PMDA, pyromellitic dianhydride.

PMDA/ODA and PMDA/DCHM were estimated from their optical band gaps. Figure 3 shows the UV/Vis absorption spectra of the PI films formed on ITO substrates (thickness: approximately $1 \mu \mathrm{m}$ ). The estimations of their optical band gaps are shown in Supplementary Figures $2-4$ in the Supplementary Information. The optical band gaps, as well as the HOMO, LUMO and LUMO +1 (from the vacuum level) energy levels and energy gaps, are summarized in Table 1. The energy gap between the HOMO and LUMO for the PMDA/DATPA $\left(E_{\mathrm{g}}=1.94 \mathrm{eV}\right)$ is much smaller than those of the PMDA/ODA and PMDA/DCHM $\left(E_{\mathrm{g}}>2.7 \mathrm{eV}\right)$, which can be attributed to the high HOMO level of the DATPA moiety. Moreover, although the spatial distributions of the LUMOs are localized around the PMDA moiety, the experimental LUMO levels decreased in the following order: PMDA/DCHM $(-3.32 \mathrm{eV})>$ PMDA/ODA
$(-3.42 \mathrm{eV})>$ PMDA/DATPA $(-3.55 \mathrm{eV})$. The variations in the LUMO levels depending on the diamine structures can be explained by increased intermolecular interactions that stabilize the unoccupied molecular orbitals (MOs). The HOMO levels and the energy gaps between the HOMOs and LUMOs, which were calculated by the density functional theory, were $(-5.41,1.85 \mathrm{eV}),(-6.43,2.81 \mathrm{eV})$ and $(-7.81,4.31 \mathrm{eV})$ for PMDA/DATPA, PMDA/ODA and PMDA/ DCHM, respectively. The calculated energy gaps qualitatively agree with the experimental data. In contrast, the variations in the calculated LUMO levels for the PMDA/DCHM $(-3.52 \mathrm{eV})$, PMDA/ ODA $(-3.62 \mathrm{eV})$ and PMDA/DATPA $(-3.56 \mathrm{eV})$ were very small because intermolecular interactions were not considered in the density functional theory calculations.

Time and temperature dependence of the electric current

To clarify the electric conduction mechanism of the PIs, the time and temperature dependence of electric current were investigated. Figure 4 shows the elapsed time dependence of the current density for a PMDA/ DATPA film measured between 40 and $230{ }^{\circ} \mathrm{C}$ in a $5 \mathrm{kV} \mathrm{cm}^{-1}$ electric field. The elapsed time dependence of current density of the other PI films is shown in the Supplementary Figures 8 and 9 in the Supplementary Information. At temperatures below $150^{\circ} \mathrm{C}$, the current density quickly decreased in the initial $10 \mathrm{~s}$ and then decreased more gradually. These time-dependent components are attributable to 'displacement current' and/or 'accumulation of charges' in the vicinity of electrodes. ${ }^{15}$ The former originates from orientation of permanent dipoles by applying electric field, that is 'orientation polarization'. In contrast, the current density was less time dependent with increasing temperature. This result occurred because the conduction of current through the dielectric insulator and semiconductors increases exponentially with increasing temperature, whereas the displacement current does not. Therefore, the time-dependent displacement current is generally dominant at lower temperatures, contributing less at higher temperatures. As shown in Figure 4, the current density after $60 \mathrm{~s}$ is 
Table 1 Estimated energy levels and band gaps for the PI films

\begin{tabular}{|c|c|c|c|c|c|c|c|}
\hline \multirow[b]{2}{*}{ Polyimides } & \multicolumn{2}{|c|}{ Optical absorption } & \multirow{2}{*}{$\begin{array}{l}L U M O+1^{a} \\
E_{\text {red }}{ }^{1 / 2}(\mathrm{eV})\end{array}$} & \multirow{2}{*}{$\begin{array}{c}\text { LUMO }^{\mathrm{a}} \\
E_{\mathrm{red}}{ }^{1 / 2}(\mathrm{eV})\end{array}$} & \multirow{2}{*}{$\begin{array}{c}\text { HOMO }^{\mathrm{a}} \\
E_{O X}{ }^{1 / 2}(\mathrm{eV})\end{array}$} & \multicolumn{2}{|c|}{ Energy gap } \\
\hline & $\lambda^{A b s}(n m)$ & $E_{\mathrm{g}}^{o p t}(\mathrm{eV})$ & & & & $E_{\mathrm{g}}(\mathrm{eV})$ & $E_{\mathrm{g}}(n m)$ \\
\hline PMDA/DATPA & 640 & 1.94 & -3.02 & -3.55 & -5.49 & 1.94 & 639.2 \\
\hline PMDA/ODA & 460 & 2.70 & -2.91 & -3.42 & $(-6.12)^{b}$ & - & - \\
\hline PMDA/DCHM & 365 & 3.40 & -2.88 & -3.32 & $(-6.72)^{b}$ & - & - \\
\hline
\end{tabular}

Abbreviations: DATPA, 4,4'-diamino-4"'-methyltriphenylamine; DCHM, diaminocyclohexylmethane; ODA, bis(4-aminodiphenyl) ether; PI, polyimide; PMDA, pyromellitic dianhydride. aEnergy levels were calculated from cyclic voltammetry and referenced to ferrocene (HOMO: $-4.8 \mathrm{eV}$ ).

${ }^{\mathrm{b}}$ Calculated from optical bandgaps (HOMO $\left.=\mathrm{LUMO}-E_{\mathrm{g}}{ }^{\mathrm{opt}}\right)$.

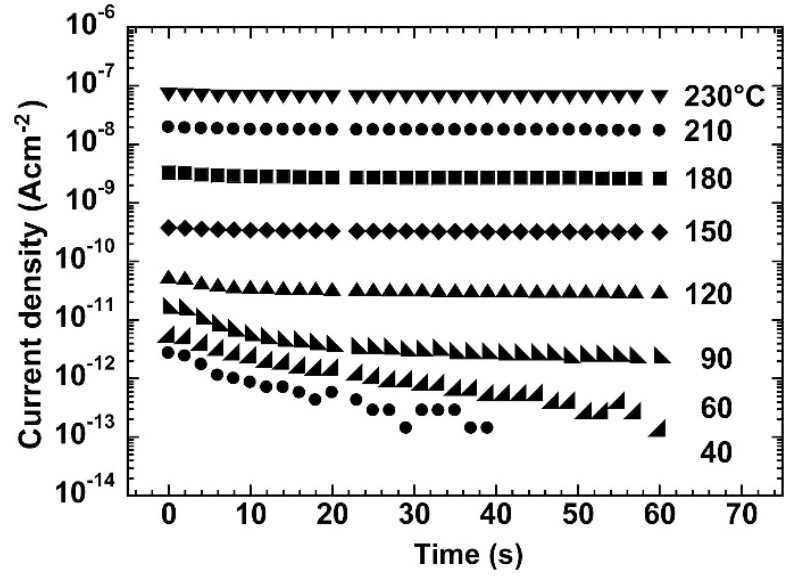

Figure 4 Elapsed time dependence of current density for a pyromellitic dianhydride (PMDA)/4, $4^{\prime}$-diamino-4"'-methyltriphenylamine (DATPA) film (2.4 $\mu \mathrm{m}$ thick) between 40 and $230^{\circ} \mathrm{C}$ under an electric field of $5 \mathrm{kV} \mathrm{cm}^{-1}$.

almost constant above $120^{\circ} \mathrm{C}$. This will be discussed in the following section.

The origin of electric carriers should be clarified to understand the electric conduction mechanisms of PIs. In this study, there are three possible origins for the electric carriers: (i) carriers that are injected from the electrodes, (ii) carriers that are thermally excited in the bulk PI, and (iii) carriers that originate from impurities such as ionic components. Because of the large differences in energy levels between the HOMO (LUMO) levels of PIs (see Table 1) and the work functions of anodic (cathodic) electrodes (ITO: approximately $4.9 \mathrm{eV}$, Ag: approximately $4.3 \mathrm{eV}$ ), a high-energy barrier against charge injection should exist at the interface between the PI and electrodes. In this case, the current density should exhibit an ohmic behavior at lower electric fields because of the absence of charge injection. The applied electric field will therefore convey only intrinsic carriers. For comparing the electric properties of the bulk PIs, electric measurements were conducted under electric fields less than $50 \mathrm{kV} \mathrm{cm}^{-1}$, a condition in which the PI films exhibited ohmic behaviors.

Figure 5 shows the inverse temperature dependence of the current density of the PI films measured at (a) $50 \mathrm{kV} \mathrm{cm}^{-1}$ and (b) $5 \mathrm{kV} \mathrm{cm}^{-1}$. The current density of the PMDA/DATPA and s-BPDA/DATPA significantly increased at temperatures above $120^{\circ} \mathrm{C}(1000 / T=2.54)$. In Table 2 , the activation energies $\left(E_{\mathrm{a}}\right)$ for the PIs above $120^{\circ} \mathrm{C}$ are calculated from the Arrhenius plots of the current densities $\left(j \propto \exp \left(-E_{\mathrm{a}} / k_{\mathrm{B}} T\right)\right.$, where $k_{\mathrm{B}}$ is Boltzmann's constant and $T$ is temperature). Under ohmic conditions, the current density is expressed as

$$
j=\sigma E=e n \mu E
$$
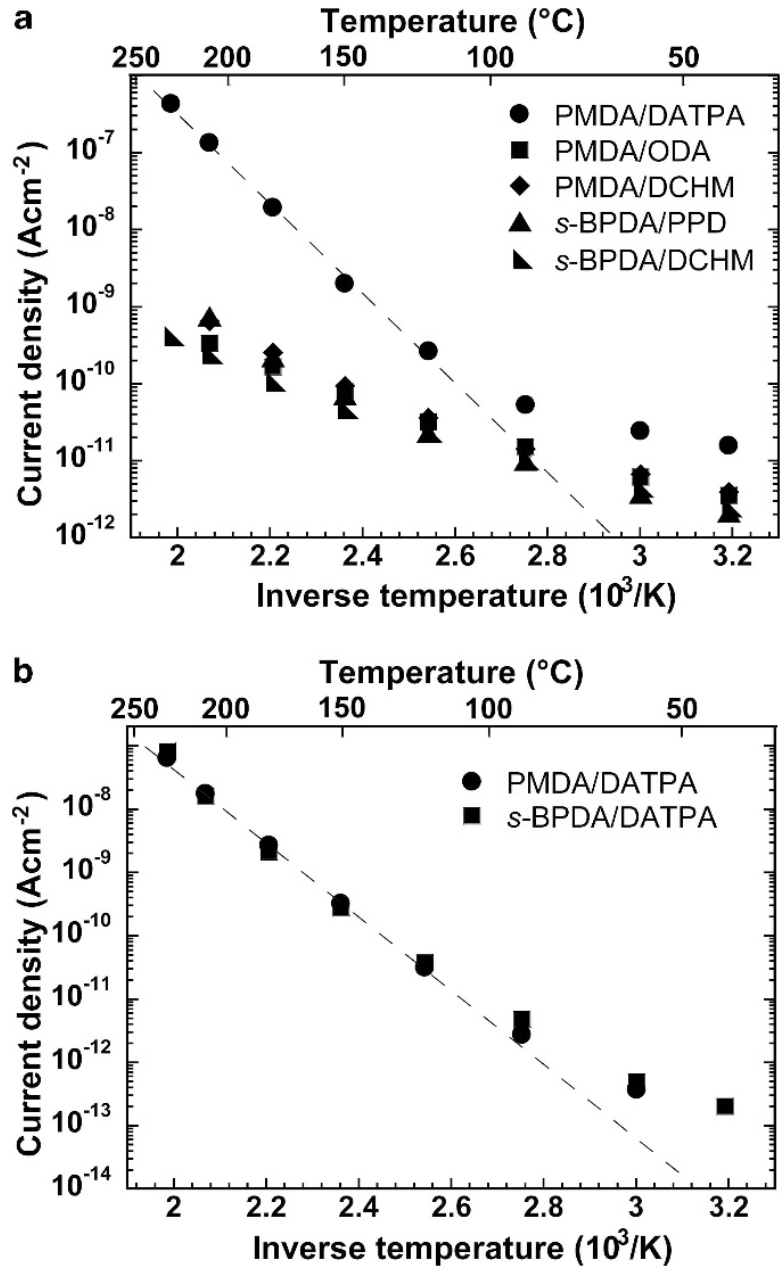

Figure 5 The temperature dependence of the current density of the polyimide (PI) films measured at (a) 50 and (b) $5 \mathrm{kV} \mathrm{cm}^{-1}$. DATPA, 4,4' diamino-4"-methyltriphenylamine; DCHM, diaminocyclohexylmethane; ODA, bis(4-aminodiphenyl) ether; PMDA, pyromellitic dianhydride; PPD, p-phenylenediamine; s-BPDA, 3,3',4,4'-biphenyltetracarboxylic dianhydride

where $\sigma$ is the conductivity, $E$ is the electric field, $e$ is the elementary charge, $n$ is the number of charge carriers and $\mu$ is the mobility of the charges. For dielectric materials at thermal equilibrium, the number of thermally excited charge carriers is expressed as follows. ${ }^{36}$

$$
n \propto \exp \left(-E_{\mathrm{g}} / 2 k_{\mathrm{B}} T\right)
$$

Amorphous polymers generally exhibit conduction behaviors characterized by charge hopping. ${ }^{36}$ In that case, the mobility of the 
Table 2 Activation energy of the current density for the PI films

\begin{tabular}{lccc}
\hline Sample & Thickness $(\mu \mathrm{m})$ & $\begin{array}{c}\text { Electric } \\
\text { field }\left(\mathrm{kV} \mathrm{cm}^{-1}\right)\end{array}$ & $\begin{array}{c}\text { Activation } \\
\text { energy }(\mathrm{eV})\end{array}$ \\
\hline PMDA/ODA & 2.4 & 50 & 0.42 \\
PMDA/DCHM & 3.2 & 50 & 0.52 \\
s-BPDA/PPD & 2.8 & 50 & 0.63 \\
s-BPDA/DCHM & 3.7 & 50 & 0.45 \\
PMDA/DATPA & 9.0 & 50 & 1.16 \\
& 2.4 & 5 & 1.17 \\
s-BPDA/DATPA & 1.7 & 5 & 1.18 \\
\hline
\end{tabular}

Abbreviations: DATPA, 4,4'-diamino-4"'-methyltriphenylamine; DCHM,

diaminocyclohexylmethane; ODA, bis(4-aminodiphenyl) ether; PI, polyimide; PMDA,

pyromellitic dianhydride; PPD, p-phenylenediamine; s-BPDA, 3,3',4,4'-biphenyltetracarboxylic dianhydride.

charges is expressed as

$$
\mu \propto \exp \left(-\Delta E / k_{\mathrm{B}} T\right),
$$

where $\Delta E$ is the activation energy determined by the potential barriers for charge hopping. According to Equations 1, 2 and 3, when the PIs exhibit electronic conduction, the current densities should be proportional to the number of thermally excited charges and their mobility. Thus, the $E_{\mathrm{a}}$ values are expressed as $\left(E_{\mathrm{g}} / 2+\Delta E\right)$. As shown in Table 2, the $E_{\mathrm{a}}$ value of the PMDA/DATPA above $120^{\circ} \mathrm{C}(1.17 \mathrm{eV})$ was larger than its $E_{\mathrm{g}} / 2$ value (see Table 1), which is indicative of a large $\Delta E$ for this PI. In contrast, the $E_{\mathrm{a}}$ of the $s$-BPDA/DATPA above $120^{\circ} \mathrm{C}(1.18 \mathrm{eV})$ was comparable to its $E_{\mathrm{g}}{ }^{\mathrm{opt}} / 2$ obtained from the optical bandgap $(1.19 \mathrm{eV}$, see Supplementary Figure 5), which is indicative of a small $\Delta E$ for this PI.

These results strongly suggest that the electronic conduction induced by thermally excited charges should be dominant in these PIs. Furthermore, the results suggest that the charge mobility of the PMDA/DATPA significantly increases with increasing temperature, whereas the charge mobility of the $s$-BPDA/DATPA is less dependent on temperature. In contrast, the temperature dependence of the current density below $120^{\circ} \mathrm{C}$ was much smaller compared with higher temperatures, indicating that the ionic current could be dominant or very influential at lower temperature because of the limited number of thermally excited carriers. Although the optical band gaps were larger for conventional PIs without TPA structures compared with the band gaps for PMDA/DATPA and s-BPDA/DATPA (see Table 1 and Supplementary Figures 3, 4, 6 and 7), the $E_{\mathrm{a}}$ values of the conventional PIs were smaller than the $E_{\mathrm{a}}$ values of the PMDA/ DATPA and $s$-BPDA/DATPA. The mobility of the ionic carriers also exhibits an exponential increase with temperature, although the number of ionic charges should be independent of temperature. As a result, there is only a small temperature dependence of the current density, as observed for PMDA/ODA, PMDA/DCHM, s-BPDA/PPD and $s$-BPDA/DCHM. This result strongly suggests that ionic conduction is dominant in these PIs over the entire temperature range, likely due to their large $E_{\mathrm{g}}$ values, which reduce and limit the number of thermally excited electrons.

\section{CONCLUSION}

The temperature dependence of the electric current density was investigated for PI films with different chemical structures to clarify the electric conduction mechanisms of PIs. The current densities of PMDA/DATPA and $s$-BPDA/DATPA containing TPA structures in their main chains exhibited significant temperature dependencies above $120^{\circ} \mathrm{C}$. The activation energies $\left(E_{\mathrm{a}}\right)$ estimated from the temperature dependencies of the current densities for these PIs were larger than the halves of their HOMO and LUMO energy gaps $\left(E_{\mathrm{g}} / 2\right)$ and optical band gaps obtained from the CV measurements and UV/Vis absorption measurements, respectively. This indicates that thermally excited electrons are the major carriers above $120^{\circ} \mathrm{C}$. In contrast, the current density of fully aromatic and semi-aliphatic PIs without TPA structures exhibited a much smaller temperature dependence over the entire temperature range, which strongly suggests that ionic conduction is dominant. This mechanism originates from the limited numbers of thermally excited carriers because of the large $E_{\mathrm{g}}$ values of these PIs. Although conventional PIs exhibit superior insulating properties, the experimental results indicate that the electronic conductivity of PIs could be enhanced by modifying their chemical structures to reduce their $E_{\mathrm{g} s}$. The introduction of the TPA structure is one promising way to enhance the electric conductivity of PIs.

\section{ACKNOWLEDGEMENTS}

This work was partly supported by Grants-in-Aid for Scientific Research from the Japan Society for the Promotion of Science $(25-288096,24-7535)$ and by JSR Co., Ltd. We thank Professor C Daniel Frisbie and Mr Bryan Paulsen for the cyclic voltammetry measurements performed at the department of chemical engineering and materials science, University of Minnesota.

1 Sroog, C. E. Polyimide. J. Polym. Sci. D 11, 161-208 (1976).

2 Hasegawa, M., Shindo, Y., Sugimura, T., Ohshima, S., Horie, K., Kochi, M., Yokota, R. \& Mita, I. Photophysical processes in aromatic polyimides. Studies with model compounds. J. Polym. Sci. B 31, 1617-1625 (1993).

3 Matsuura, T., Ando, S., Sasaki, S. \& Yamamoto, F. Polyimides Derived from 2,2'Bis(trifluoromethyl)-4,4'-diaminobiphenyl. 4. Optical Properties of Fluorinated Polyimides for Optoelectronic Components. Macromolecules 27, 6665-6670 (1994).

4 Aleksandrova, E. L. Structural properties of polyimides and the mechanism of carrier photogeneration in polyimide-based molecular complexes. Opt. Spectrosc. 93, 128-135 (2002).

5 Ling, Q. D., Chang, F. C., Song, Y., Zhu, C. X., Liaw, D. J., Chan, D. S. H., Kang, E. T. \& Neoh, K. G. Synthesis and dynamic random access memory behavior of a functional polyimide. J. Am. Chem. Soc. 128, 8732-8733 (2006).

6 Hsiao, S. H., Chang, Y. M., Chen, H. W. \& Liou, G. S. Novel Aromatic Polyamides and Polyimides Functionalize with 4-tert-Butyltriphenylamine Groups. J. Polym. Sci. A 44, 4579-4592 (2006).

7 Wakita, J., Sekino, H., Sakai, K., Urano, Y. \& Ando, S. Molecular Design, Synthesis, and Properties of Highly Fluorescent Polyimides. J. Phys. Chem. B 113, 15212-15224 (2009).

8 Wakita, J., Sekino, H., Inoue, S., Kawanishi, N. \& Ando, S. Excited-state intramolecular proton transfer in imide compounds and its application to control the emission colors of highly fluorescent polyimides. Macromolecules 43, 3594-3605 (2010).

9 Huang, L. T., Yen, H. J. \& Liou, G. S. Substituent effect on electrochemical and electrochromic behaviors of ambipolar aromatic polyimides based on aniline derivatives. Macromolecules 44, 9595-9610 (2011).

10 Hanscomb, J. R. \& Calderwood, J. H. Thermally assisted tunnelling in polyimide film under steady-state and transient conditions. J. Phys. D 6, 1093-1104 (1973).

11 Adamec, V. \& Calderwood, J. H. Electrical conduction in dielectrics at high fields. J. Phys. D 8, 551-560 (1975).

12 Rothman, L. B. Properties of thin polyimide films. J. Electrochem. Soc. 127, 2216-2220 (1980)

13 Sawa, G., Nakamura, S., lida, K. \& leda, M. Electrical conduction of polypyromellitimide films at temperatures of $120-180^{\circ} \mathrm{C}$. Jpn J. Appl. Phys. 19, 453-458 (1980).

14 Sharma, B. L. \& Pillai, P. K. C. Electrical conduction in Kapton polyimide film at high electrical fields. Polymer (Guildf). 23, 17-20 (1982).

15 Sessler, G. M., Hahn, B. \& Yoon, D. Y. Electrical conduction in polyimide films. J. Appl. Phys. 60, 318-326 (1986)

16 Iwamoto, M., Fukuda, A. \& Itoh, E. Spatial distribution of charges in ultrathin polyimide Langmuir-Blodgett films. J. Appl. Phys. 75, 1607-1610 (1994).

17 Lee, S. A., Yamashita, T. \& Horie, K. Photoconductivity of aliphatic polyimide. J. Photopolym. Sci. Technol. 9, 355-362 (1996).

18 Lee, S. A., Yamashita, T. \& Horie, K. Photoconductivity of a polyimide with an alicyclic diamine doped with $N, N, N^{\prime}, N^{\prime}$-tetramethyl-p-phenylenediamine. Polym. J. 29, 752-758 (1997).

19 Lee, S. A., Yamashita, T. \& Horie, K. Photoconductivity of a polyimide with an alicyclic diamine: charge carrier photogeneration in the mixed layer packing arrangement. J. Polym. Sci. B 36, 1433-1442 (1998).

20 Takizawa, K., Wakita, J., Kakiage, M., Masunaga, H. \& Ando, S. Molecular aggregation structures of polyimide films at very high pressure analyzed by synchrotron wide-angle X-ray diffraction. Macromolecules 43, 2115-2117 (2010). 
21 Matsumoto, T. Semiaromatic polyimides based on bis(aminomethyl)bicyclo[2.2.1] heptane. High Perform. Polym 11, 367-377 (1999).

22 Oishi, Y., Ogasawara, K., Hirahara, H. \& Mori, K. Synthesis of Alicyclic Polyimides by the Silylation Method. J. Photopolym. Sci. Technol. 14, 37-40 (2001).

23 Oishi, Y., Kikuchi, N., Mori, K., Ando, S. \& Maeda, K. Synthesis of alicyclic polyimides from fluorinated alicyclic diamine. J. Photopolym. Sci. Technol. 15, 213-214 (2002).

24 Takizawa, K., Wakita, J., Azami, S. \& Ando, S. Relationship between molecula aggregation structures and optical properties of polyimide films analyzed by synchrotron wide-angle X-ray diffraction, infrared absorption, and UV/Visible absorption spectroscopy at very high pressure. Macromolecules 44, 349-359 (2010).

25 Takizawa, K., Wakita, J., Sekiguchi, K. \& Ando, S. Variations in aggregation structures and fluorescence properties of a semialiphatic fluorinated polyimide induced by very high pressure. Macromolecules 45, 4764-4771 (2012).

26 Lee, C., Yang, W. \& Parr, R. G. Development of the Colle-Salvetti correlationenergy formula into a functional of the electron density. Phys. Rev. B 37, 785-789 (1988).

27 Miehlich, B., Savin, A., Stoll, H. \& Preuss, H. Results obtained with the correlation energy density functionals of becke and Lee, Yang and Parr. Chem. Phys. Lett. 157, 200-206 (1989).
28 Becke, A. D. Density-functional thermochemistry. III. The role of exact exchange. J. Chem. Phys. 98, 5648-5652 (1993).

29 Ando, S., Fujigaya, T. \& Ueda, M. Density functional theory calculations of photoabsorption spectra of organic molecules in the vacuum ultraviolet region. Jpn J. Appl. Phys. 41, L105-L108 (2002).

30 Ando, S., Fujigaya, T. \& Ueda, M. DFT calculations of photoabsorption spectra in the VUV region for design of photoresist materials for $157 \mathrm{~nm}$ Lithography. J. Photopolym Sci. Tech. 15, 559-568 (2002).

31 Ando, S. \& Ueda, M. DFT calculations of photoabsorption spectra for alicyclic and heterocyclic compounds in the VUV region. J. Photopolym. Sci. Tech. 16, 537-544 (2003).

32 Slonimskii, G., Askadskii, A. \& Kitaigodorodskii, A. The packing of polymer molecules. Polym. Sci. USSR 14, 556-557 (1970).

33 Bondi, A. J. van der Waals Volumes and Radii Phys. Chem. 68, 441-451 (1964).

34 Frisch, M. J. Gaussian 09, Revision B.01 (Gaussian, Inc., Wallingford CT, 2010).

35 Viehbeck, A., Goldberg, M. J. \& Kovac, C. A. Electrochemical properties of polyimides and related imide compounds. J. Electrochem. Soc. 137, 1460-1466 (1990).

36 Hans, M. in Organic Semiconductors: Dark- and Photoconductivity of Organic Solids (ed. Ebel, H. F.) Ch. 8, 269-306 (Verlag Chemie, Weinheim, Germany, 1974).

Supplementary Information accompanies the paper on Polymer Journal website (http://www.nature.com/pj) 